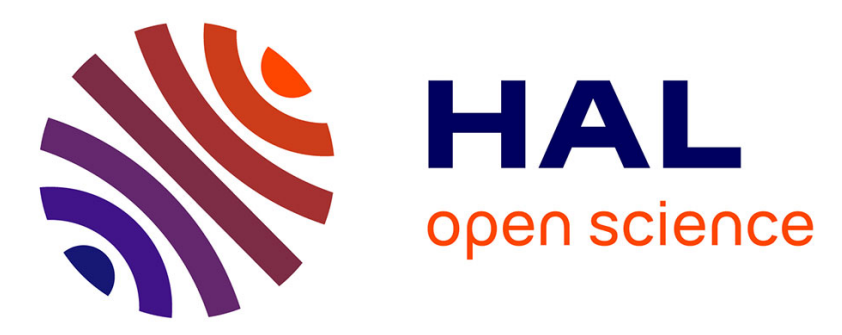

\title{
Analysis of eating disorders among 12-17 year-old adolescents in the island of Gran Canaria
}

Covadonga Mateos-Padorno, Stéphanie Scoffier-Mériaux, Maria José

Martínez-Patiño

\section{- To cite this version:}

Covadonga Mateos-Padorno, Stéphanie Scoffier-Mériaux, Maria José Martínez-Patiño. Analysis of eating disorders among 12-17 year-old adolescents in the island of Gran Canaria. Eating and Weight Disorders - Studies on Anorexia, Bulimia and Obesity, 2013. hal-02524739

\section{HAL Id: hal-02524739 \\ https://hal.univ-cotedazur.fr/hal-02524739}

Submitted on 6 Apr 2020

HAL is a multi-disciplinary open access archive for the deposit and dissemination of scientific research documents, whether they are published or not. The documents may come from teaching and research institutions in France or abroad, or from public or private research centers.
L'archive ouverte pluridisciplinaire HAL, est destinée au dépôt et à la diffusion de documents scientifiques de niveau recherche, publiés ou non, émanant des établissements d'enseignement et de recherche français ou étrangers, des laboratoires publics ou privés. 


\title{
$\underset{B E P O R T}{B R I E F}$ Analysis of eating disorders among 12-1 7 year-old adolescents in the island of Gran Canaria
}

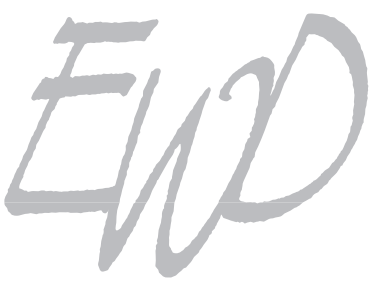

Key words:

Eating disorder, Eating Attitude Test (EAT-40), prevalence, Gran Canaria.

Correspondence to:

Prof. Covadonga Mateos Padorno, PhD, Departamento de Educación Física,

Universidad de Las Palmas de Gran Canaria, Campus de Tafira, 35017 Las Palmas de Gran Canaria, Las Palmas.

E-mail:

cmateos@def.ulpgc.es

Received: November 20, 2009

Accepted: March 15, 2010

\author{
C. Mateos-Padorno ${ }^{1}$, S. Scoffier², M. Polifrone ${ }^{3}$, M.J. Martínez-Patiño ${ }^{4}$, \\ A. Martínez-Vidal ${ }^{4}$, and M.L. Zagalaz Sánchez ${ }^{5}$
}

${ }^{1}$ Departamento de Educación Física, Universidad de Las Palmas de Gran Canaria, Spain, ${ }^{2}$ Université de Nice Sophia-Antipolis, France, 32Department of Research, Development and Innovation, Seaweed Canarias S.L., Spain, ${ }^{4}$ Departamento de Didácticas Especiales, Universidad de Vigo, Spain, ${ }^{5}$ Departamento de Didácticas de la Expresión Musical, Plástica y Corporal, Universidad de Jaén, Spain

\begin{abstract}
A clinical pathology characterized by disturbances in eating behaviour has been often associated to socio-cultural factors that influence the psychopathology of these disorders. The alarming increase in the number of teenagers with eating disorders underscores the need to promote research on the underlying causes, and to identify high-risk subpopulations in need of effective targeted treatment. The objective of this study was to assess the prevalence of eating disorders among an adolescent population of both sexes on the island of Gran Canaria. The sample was composed of adolescent boys and girls aged 12 to 17 years old $(N=1364)$ who resided in different municipalities of Gran Canaria. The EAT-40 questionnaire was administered (cut-off point at 30), and body mass index measurements were assessed. The mean BMI for the 1364 subjects was $21.8 \mathrm{Kg} / \mathrm{m}^{2} ; 15 \%$ were underweight, and of these at least $1 \%$ obtained BMI values below $15 \mathrm{Kg} / \mathrm{m}^{2}$. Thus, $13.4 \%$ of adolescents were potentially at risk of eating disorders according to the EAT-40 questionnaire. Moreover, the BMI was not significantly correlated to the EAT-40 and was not considered a sufficient parameter to establish the incidence of eating disorders.

(Eating Weight Disord. 15: e190-e194, 2010). ๑2010, Editrice Kurtis
\end{abstract}

\section{INTRODUCTION}

Many theoretical frameworks have been developed to explain the personal and contextual factors that govern eating disorders $(1,2)$. The sociocultural influences are promoted by family, peers, medias, advertising, and cultural and social norms of the society (1). In recent decades, mass media imposed standards and cultural attitudes of physical attractiveness (embodied in images of extenuated models who reflect lives of wealth, health, happiness, and success), which are presumed to be contributing factors for the surge in the obsession of physical fitness as a priority of modern-day societies $(3,4)$. New standards of beauty, social success and the media have been blamed for the increase in these disorders. These values have begun to trickle down from the adults in the population to the children (5). Research now shows that many children are dissatisfied with their bodies. Specifically, girls wish to be thinner and boys wish to be more muscular (6). Various factors are associated with body image problem including BMI, self-esteem, body importance and body composition (7). This distorted reality of dismorphophobic mirrors has been reported to induce phobia to fat, obesity and the obese $(7,8)$. Thus, these recent physical norms promoted the emergence of Eating disorders and disordered eating.

In addition, during the pubertal period the child's body undergoes rapid transformation and adopts the characteristics of the adult body. During this phase of the life, young people experiment modifications in their corporal silhouette and changes in their hormonal and psychological pattern, so that they represent the most vulnerable part of the population to eating disorders. The persecution of a thin body constitutes one of adolescence more ingrained characteristics and female adolescents are most vulnerable to eating disorders $(9,10)$. In fact, teenagers are exposed to the influence of thousands of messages expounding the benefits and disadvantages of the thinness, which reflect and implement inside their group of friends. 
In this phase of child development, any corporal characteristic that makes the teenager believe to possess significant differences compared with others can unleash important worries and, which is more transcendental, the decision to slim (11). Therefore, it appears that adolescence is a propitious period to develop serious disturbances in eating behaviours. The increasing disparity between popularized conceptions of the "ideal body" may explain the increased prevalence of eating disorders among adolescents.

The term "disordered eating attitudes" describes unhealthy attitudes and behaviour that range from strict dietary habits in order to lose or maintain weight to the severe food restriction of anorexia (12). The Diagnostic and Statistical Manual of Mental Disorders (DSMIV-TR) (13) published by the American Psychiatric Association identifies three eating disorders i.e., Anorexia Nervosa, Bulimia Nervosa and ED-NOS.

Anorexia Nervosa is an eating disorder characterized by an obsessive fear of gaining weight, self-starvation, and body image distortion. A disturbance in the perception of body shape and weight (dismorphophobia) is an essential feature of both conditions. The DSMIV-TR specifies two subtypes of anorexia: a) the restricting type, accomplished primarily through dieting, fasting, or excessive exercise but not through regular binge-eating or purging behaviour; b) the binge-eating type or purging type, which conduct falls outside the normal disposal of food refusal and where weight loss involves regular binge-eating or purging behaviour i.e., self-induced vomiting, or the misuse of laxatives, diuretics, or enemas.

Bulimia Nervosa is an eating disorder denoted by episodes in which a person feels a compulsive need to ingest an exorbitant and disproportionate amount of food and then uses various methods to succeed in not metabolizing and gaining weight. In the same way, two types of bulimia nervosa have been described: a) with supply of elimination, in which the subject continues to self-induce vomiting and/or makes inappropriate use of laxatives, diuretics or enemas; b) without elimination, in which the person regularly adopts bulimic compensatory behaviors, but without engaging in selfinduced vomiting or use of laxatives, diuretics or enemas.

A further category, Eating Disorders Not Otherwise Specified (ED-NOS), is provided for coding disorders that do not meet the criteria for either anorexia nervosa or bulimia nervosa (13). For example, binge eating disorder, which is characteristic of people who suffer episodes of binging or purging but not so frequently enough to warrant a diagnosis of bulimia nervosa, or who show symptoms of anorexia nervosa but still have a normal body mass index. The body mass index (BMI) is a measure of individual's weight in relation to height, and is a method frequently employed to evaluate the risk of eating disorders (14). However, BMI is not valid in childhood or for a small or tall person (15), and is judged as controversial due to the limits of the parameters considered and because it does not differentiate body composition. Several studies have associated the BMI to disturbances in eating attitudes and behaviours (16-18).

Also available are different screening procedures for the measure of the incidence of eating disorders, such as the 40-items Eating Attitudes Test (EAT-40) (19) and its reduced version 26-items Eating Attitudes Test (EAT$26)$, the Eating Disorders Inventory (EDI), the Restrained Eating Inventory (EI), among others. Among them, the EAT-40 and the EAT-26 are the most reliable and highly correlated (20). The EAT-40 is a useful screening tool, which allows to identify the eating concerns and the emotional disturbance of these pathologies (21).

Gran Canaria island is situated in the Canary Archipelago (Spain) in the Atlantic Ocean. The latitude where the islands are situated presents special atmospheric conditions which allow the existence of a climatologically stable and moderate environment so as to make the islands deserve the denomination of "las islas afortunadas" ("the fortunate islands"). These particular conditions attract thousands of tourists every year to enjoy the pleasure of beach and sun. In this framework, the youngest part of the population could be considered the most exposed to the pressure of the stereotype of a slim body to show in public, not only during summer as occurs in the Iberian peninsula and other European countries, but throughout the year, so that the incidence of eating disorders could be enhanced by the surrounding environment.

To our knowledge, the prevalence of eating disorders among adolescents has not been documented in the island of Gran Canaria (Spain). Thus, the aim of the present study was to screen the population of adolescents in Gran Canaria for eating disorders using the standardized EAT-40 questionnaire and the BMI. In line with previous research, we also presume that girls would be most vulnerable to eating disorders than boys $(11,22-24)$ and that the BMI would be positively correlated to eating disorders in girls (16-18). 


\section{METHOD}

Participants and Procedure

A cohort of 1817 voluntary adolescents from 14 educational centers was randomly selected among the public schools in Gran Canaria. 1364 of them were retained for the study $\left(\mathrm{N}_{\text {males }}=492,36.1 \%\right.$; $\left.\mathrm{N}_{\text {females }}=872,63.9 \%\right)$ after scrutinizing for age, completion of questionnaire and the presence of informed consent by parents. All participants were aged from 12 to 17 years $\left(\mathrm{M}_{\mathrm{age}}=14.73 ; \mathrm{SD}=1.23\right)$ (cf. Fig. 1$)$.

\section{Measure}

The Eating Attitudes Test (EAT-40) is a screening tool for eating disorders developed by Garner and Garfinkel (19). It is an objective self-report questionnaire consisting of 40 questions that are answered by using a 6-point Likert-type scale ranging from "never" to "always." Only the three most extreme scores are assigned a point value from 1 to 3 , resulting in total scores that can range from 0 to 120 . Any subject who has a total score of 30 or above on the EAT is considered to be "at risk" for eating disorder behaviour and symptomatology $(25,26)$. The authors consider the cut-off at 30 where the EAT-40 indicates possible symptoms of eating disorders.

Questionnaire completion was carried out under standardized conditions, i.e. paper, pencil, prohibition to communicate in order to avoid interchange of information, and a maximum 20-minute questionnaire completion time to promote the prompt answer and avoid bias due to intentional coverage of information.

In the present study, the BMI has been considered as complementary measurements due to its common use in clinical practice, and because it is straightforward and relatively cheap to obtain (27). The BMI has been calculated on the basis of the height and weight of students, measured with a measuring rod mobile platform (SECA 6611, range of measurements from $54 \mathrm{~cm}$ to $200 \mathrm{~cm}$, s.e. $\pm 1 \mathrm{~mm}$ ) and electronic balance (Tefal Evidence Maxi, range of measurements from $0 \mathrm{~g}$ to $130 \mathrm{Kg}$, s.e. $\pm 0.1 \mathrm{Kg}$ ), and classified according to Saldaña (28) in the following classes: $<18 \mathrm{Kg} / \mathrm{m}^{2}$ severe underweight; $18-19.99 \mathrm{Kg} / \mathrm{m}^{2}$ underweight; $20-24.99 \mathrm{Kg} / \mathrm{m}^{2}$ normal weight; 25 $29.99 \mathrm{Kg} / \mathrm{m}^{2}$ overweight; $>30 \mathrm{Kg} / \mathrm{m}^{2}$ obesity.

\section{Analysis of data}

The data gathered from this study were analyzed using the SPSS 14.0.1 computer software. The alpha of Cronbach, based on the mean inter-elements correlation, has been used to define the level of internal consistency of the

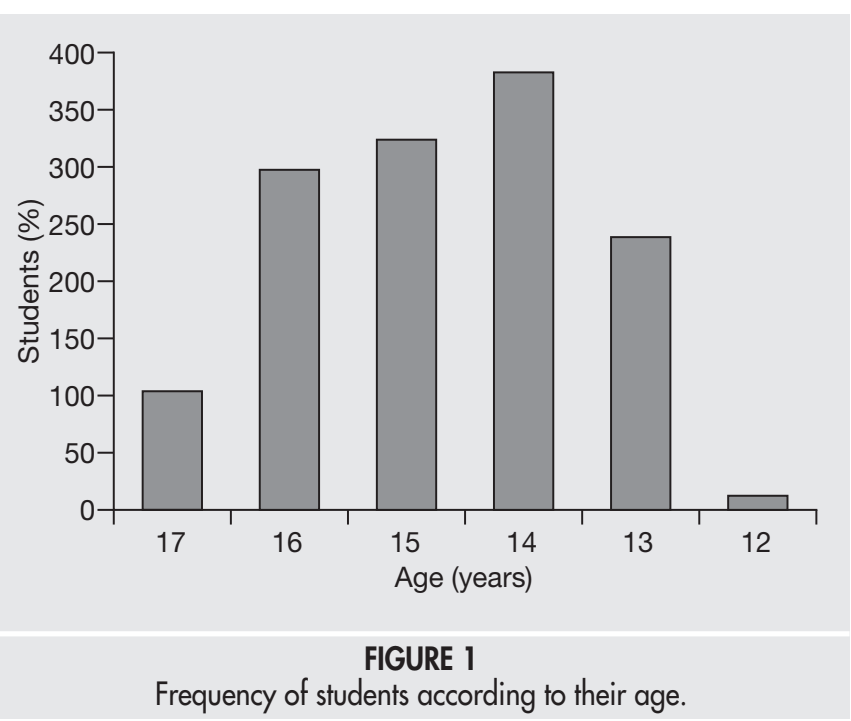

questionnaire and its reliability. The EAT-40 showed a validity coefficient of 0.87 and an internal consistency coefficient of 0.79 which is acceptable. Descriptive analysis (mean, maximum and minimum, number of cases) was performed on the BMI and the EAT-40 answers. Frequency of cases analysis has been performed to relate BMI to the EAT-40.

\section{RESULTS}

The average of BMI value for the 1364 subjects was $21.8 \mathrm{Kg} / \mathrm{m}^{2}$; $15 \%$ were underweight, and of these at least $1 \%$ obtained BMI values below $15 \mathrm{Kg} / \mathrm{m}^{2}$ i.e., at risk of eating disorders (Fig. 2). A total of $86.6 \%$ of subjects scored below 30 on the EAT-40 whereas $13.4 \%$ scored above 30 , which is indicative of different degrees of eating disturbances. In terms of gender, $14.5 \%$ of girls and $11.6 \%$ of boys scored 30 or more on the EAT-40. The average in the EAT-40 for girls was 32, the highest 94, and the lowest 1 . In boys the average in the EAT-40 was 34 , the highest 62 , and the lowest 2.

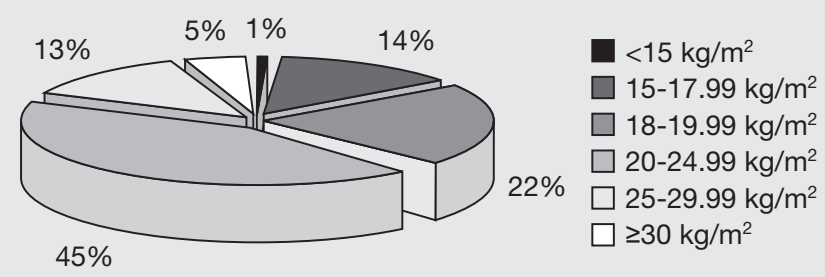

FIGURE 2

Body Mass Index of Gran Canaria adolescents. 


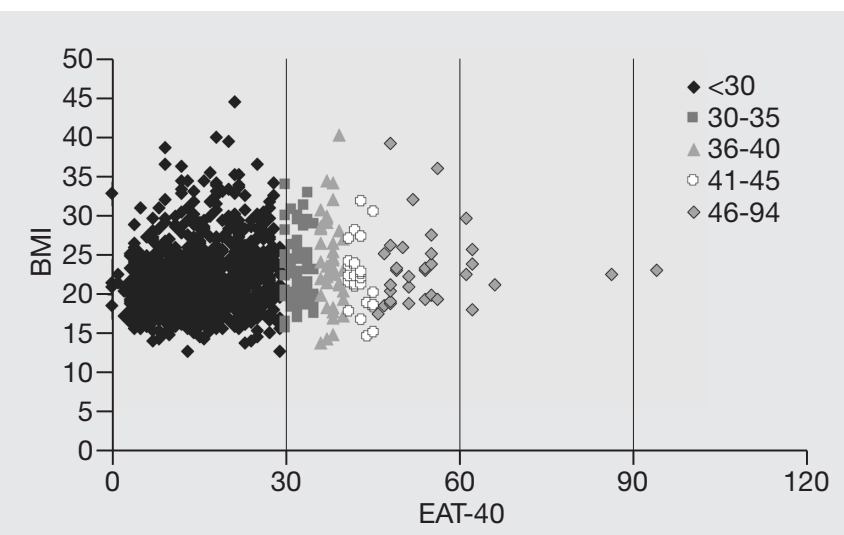

FIGURE 3

Body Mass Index vs 40-items Eating Attitudes Test of Gran Canaria adolescents.

The correlation analysis undertaken between BMI and total EAT-40 scores was significant $(r=0.18 ; p<0.01)$. However, a scatterplot analysis revealed a particular relation between the BMI and EAT-40 scores. Indeed, subjects with a BMI below $18 \mathrm{Kg} / \mathrm{m}^{2}$ and higher than $30 \mathrm{Kg} / \mathrm{m}^{2}$ present unlike values of EAT-40, equally to other categories observed previously (Fig. 3).

\section{DISCUSSION}

The number of female and male schoolattending adolescents with eating disorders, as determined by means of the EAT-40 questionnaire and BMI data on corporal weight and height, was similar to some reports in other Spanish populations. For example, in Reus, a study of 520 adolescents showed that $15.3 \%$ of girls aged 13 years and $13.6 \%$ of boys aged 14 obtained a "pathological" score of 30 or above on the EAT-40 (22). In our study, a $13.4 \%$ of the sample was considered at risk of eating disorders, as defined by a score equal to or greater than 30 on the EAT-40. In line with other studies $(11,22-24)$, the observation of EAT-40 equal or above 30 was greater in females than males: $14.5 \%$ of females and $11.6 \%$ of males, but the difference between sexes was not marked.

On the contrary, a study of 1264 adolescents aged 12 to 19 years old in Barcelona reported a difference more noticeable between sexes: $9.8 \%(\mathrm{~N}=56)$ of girls and $1.2 \%(\mathrm{~N}=8)$ of boys obtained "pathological" scores of 30 or above on the EAT-40 (11). Similarly, in a sample of 515 adolescents, Carbajo et al. (29) observed "pathological" scores of 30 or above on the EAT-40 in $12.4 \%$ girls and $8.3 \%$ in boys. Comparable results have been obtained in Castilla and León, where $12.3 \%$ girls and $3.2 \%$ boys showed EAT-40 of 30 or above (24). In Madrid, a research on 1543 adolescents aged 12 to 21 years old revealed a prevalence of $5.13 \%$ for girls and $0.64 \%$ for boys (23).

Also $13 \%$ of the cohort was considered to present underweight and only $1 \%$ presented severe underweight on the basis of BMI, but no significant relationship between BMI and EAT-40 scores has been observed through a direct correlation of the two indexes, suggesting that the perception of eating attitudes among Gran Canaria adolescents did not correspond to their physical state. The eating disorders are a complex illness with a high psychological component and the direct BMI reflects only the physical status of the subjects. The use of this index could be indicative of a situation of risk but should always be accompanied by other components and parameters, which help in the identification of eating disorders.

Several limitations of the current series of studies must be taken into account when interpreting these findings. First, the data was mostly self-reported and thus may have been biased by social desirability. Then, this study was cross-sectional, which limits the stability across time of the relationships between variables. In conclusion, this study confirms the limitations to use the BMI as unique parameter to assess eating disorders and to corroborate the presence of a relatively high percentage of subjects, which presented high scores of EAT40 and consequently assesses the need to follow them for a complete diagnosis in order to avoid the insurgence of deeper health problems. Also the hypothesis that girls are more affected by eating disorders than males is not confirmed by the EAT-40 in this study, since the score at 30 did not show a marked difference between the two sexes.

In the future, further research will be required to identify culture-specific factors and ascertain their impact on the prevalence of eating disorders in Gran Canaria. Indeed, eating disorders are serious and complex problems, arising from a wide scope of physical, emotional, social, and family factors that must be assessed to address the need for effective prevention and treatment. Moreover, eating disorders are related to a cultural obsession with slenderness as a physical, psychological, and moral issue. So, in both male and female Gran Canaria adolescents, the development of selfesteem and self-respect in a variety of spheres (i.e. school, work, community service, and hobbies) could transcend their physical appearance. If our findings are confirmed and specified, programs to prevent disordered eating 
attitudes in adolescents could be more specifically adapted to address these issues. Not least, improvements could be made in the management of training programs for the sports sessions and in the approaches to adolescents' health maintenance.

\section{REFERENCES}

1. Jacobi C, Hayward C, de Zwaan M, et al. Coming to terms with risk factors for eating disorders: application of risk terminology and suggestions for a general taxonomy. Psychol Bull 2004; 130: 19-65.

2. Striegel-Moore RH, Bulik CM. Risk factors for eating disorders. Am Psychol 2007; 62: 181-98.

3. Becker AE, Burwell RA, Gilman SE, et al. Eating behaviours and attitudes following prolonged exposure to television among ethnic Fijian adolescent girls. Br J Psychiatry 2002; 180: 509-14.

4. Becker AE, Hamburg P. Culture, media, and the eating disorders. Harv Rev Psychiatry 1996; 4: 163-7.

5. McCabe MP, Ricciardelli LA. The development of the perceived sociocultural influences on body image and body change questionnaire. Int J Behav Med 2001; 8: 19-41.

6. Thomas K, Ricciardelli LA, Williams RJ. Gender traits and self-concept as indicators of problem eating and body dissatisfaction among children. Sex Roles 2000; 43: 441-58.

7. Cusumano DL, Thompson JK. Body image and body shape ideals in magazines: exposure, awareness, and internalization. Sex Roles 1997; 37: 701-21.

8. Stice E, Shaw H. Eating disorder prevention programs: A meta-analytic review. Psychol Bull 2004; 13 : 206-27.

9. De Castro JM, Goldstein SJ. Eating attitudes and behaviors of pre- and postpubertal females: clues to the etiology of eating disorders. Physiol Behav 2005; 58: 15-23.

10. Killen JD, Hayward C, Litt I, et al. Is puberty a risk factor for eating disorders? Am J Dis Child 1992; 146: 323-5.

11. Toro J, Castro J, García M, et al. Eating attitudes, sociodemographic factors and body shape evaluation in adolescence. Br J Med Psychol 1989; 62: 61-70.

12. Hobart JA, Smucker DR. The female athlete triad. Am Fam Physician 2000; 61: 3357-64.

13. American Psychiatric Association. Diagnostic and statistical manual of mental disorders. DSM-IV-TR (4th Edition). Washington DC, APA, 1994, pp 539-50.

14. Hebebrand J, Himmelmann GW, Heseker H, et al. Use of percentiles for the body mass index in anorexia nervosa: Diagnostic, epidemiological, and therapeutic considerations. Int J Eat Disord 1998; 19: 359-69.

15. Cole TJ, Bellizzi MC, Flegal KM, et al. Establishing a standard definition for child overweight and obesity worldwide: international survey. Br Med J 2000; 320: 1240-3.

16. Jones J, Bennett $S$, Olmsted M, et al. Disordered eating attitudes and behaviours in teenaged girls: a schoolbased study. Can Med Assoc J 2001; 165.

17. Johnson-Sabine E, Woods K, Patton G, et al. Abnormal eating attitudes in London schoolgirls - a prospective epidemiological study: factors associated with abnormal response on screening questionnaires. Psychol Med 1988; 18: 615-22.

18. Neumark-Sztainer D, Hannan PJ. Weight-related behaviors among adolescent girls and boys: results from a national survey. Arch Pediatr Adolesc Med 2000; 154: 569-77.

19. Garner DM, Garfinkel PE. The Eating Attitudes Test: An index of the symptoms of anorexia nervosa. Psychol Med 1979; 9: 273-9.

20. Berland NW, Thompson JK, Linton PH. Correlation between the EAT-26 and the EAT-40, the Eating Disorders Inventory and the Restrained Eating Inventory. Int J Eat Disord 2006; 5: 569-74.

21. Cervera S, Lahortiga F, Martinez-Gonzalez MA, et al. Neuroticism and low self-esteem as risk factors for incident eating disorders in a prospective cohort study. Int J Eat Disord 2003; 33: 271-80.

22. Canals J, Barceló R, Domènech E. Cuestionario de actitudes alimentarias EAT en una población de edad puberal. Revista de Psiquiatría Infantil 1990; 4: 265-8.

23. Peláez MA. Estudio epidemiológico de los TCA en población escolarizada de la comunidad de Madrid. Tesis doctoral. Departamento de psicología clínica experimental, Universidad Complutense de Madrid, 2002.

24. Vega T, Rasillo MA, Lozano JE. Estudio del riesgo de trastornos de la conducta alimentaria en estudiantes de enseñanza de secundaria de Castilla y León. En Junta de Castilla y León. Trastornos de la conducta alimentaria en Castilla y León. España, Lovader, 2001, pp 27-62.

25. Loureiro-Cachón VE. Comportamiento anoréxico en la población adolescente femenina de tercero de BUP del municipio de La Coruña. PhD Thesis, Universidad de Santiago de Compostela, 1994.

26. Rodríguez-Cano T, Beato-Fernández L, BelmonteLlario A. New contributions to the prevalence of eating disorders in Spanish adolescents: detection of false negatives. Eur Psychiatry 2005; 20: 173-8.

27. Lindsay RS, Hanson RL, Roumain J, et al. Body mass index as a measure of adiposity in children and adolescents: relationship to adiposity by dual energy x-ray absorptiometry and to cardiovascular risk factors. J Clin Endocrinol Metab 2001; 86: 4061-7.

28. Saldaña C. Trastornos del comportamiento alimentario. Madrid, Fundación Universidad Empresa, 1994.

29. Carbajo G, Canals J, Fernández J, et al. Cuestionario de actitudes alimentarias en una muestra de adolescentes: dos años de seguimiento. Psiquis 1995; 16: 21-6. 